\title{
The Effect of A Structured Training Program on Intensive Care Nurses Performance
}

\author{
Ishraga Mohamed $^{1^{*}} \quad$ Elham Elhanafy ${ }^{2}$ \\ 1.Medical-Surgical Nursing Dep., College of Nursing. Taibah University, K.S.A \\ Assistant professor of Critical Care Nursing. Faculty of Nursing Sciences, Alnilain University. Sudan \\ 2.Assistant professor, Nursing Administration Dep. Faculty of Nursing, Damanhour University, Egypt \\ Associate professor of Nursing Administration. Nursing College. Taibah University. K.S.A.
}

\begin{abstract}
Background: An intensive care unit is that area of a hospital where patients' serious illnesses or injuries receive special medical and nursing care. ICU nurses are highly knowledgeable and skilled health care professionals that work in an ICU in association with other members of the hospital team to provide optimum patient care. The care of the mechanically ventilated patient is an essential component of a nurse's clinical practice in the intensive care units (ICUs), therefore it seems natural to devote a great deal of work in preparing and training staff before allowing them to work with patients. Aim: to evaluate the effect of a structured training program on intensive care nurses' performance. Design: A quasi-experimental pre and posttest research design was used. Setting: Two teaching hospitals, Al-Shabaab and Al- Khartoum in Khartoum, Sudan. Sample: Purposive sample of intensive care nurses' working in the two hospitals, (50, 30nurses) from Al- Khartoum, and-Shabaab hospitals. Tools: Two tools were used; the first tool questionnaire developed by researchers and checklist, the second tool: McCloskey/Mueller Satisfaction Scale (MMSS) was used for data collection. The study result; there is a positive effect of educational program on enhancing nurses' knowledge, about mechanical ventilation in general, and there were a highly statistically significant difference between nurses' knowledge and their performance at pre and post intervention program, However there was no correlation between nurses' socio-demographic variables and their knowledge of pre and post intervention program. Conclusion and Recommendations ; the education program had a positive effect on the nurses' attitudes toward mechanically ventilated patient.; the educational programs for all nursing members should be applied as continuing education, and further studies should be carried out with bigger sample and longer time.
\end{abstract}

Keywords: China insurance industry, Foreign fund, Challenge

DOI: $10.7176 / \mathrm{JHMN} / 60-07$

Publication date:March $31^{\text {st }} 2019$

\section{Introduction}

Intensive care unit (ICU) provides severe medical treatment to the most ill or injured patients in the hospital. These patients have need of continuous monitoring and sophisticated medical treatment. The serious patient is frequently attached to mechanical ventilation and monitors', which provides supportive care required to prolong life. The skills and knowledge of critical care nurses possibly will be directed towards health promotion, crisis interference, maintenance and treatment of critical patients. Training primarily focuses on teaching organizational members how to perform their current jobs and helping them performs, ICU nurses can sustain professional competence through ongoing education, training, research and skill development and attempt provide evidence-based practice through the promotion of research within their specialty areas (10).

Care of a mechanically ventilated patient has become an integral part of nursing care in a critical area or general medical-surgical units, extended care facilities, nurses, physicians, and respiratory therapists need to understand each patient's specific pulmonary problems and work together to set realistic goals. In addition, Effective collaboration with them requires open, extensive, and coordinated communication as well as shared team goals that will result in improved quality of management, patient safety, and discharge outcomes. Furthermore, Both doctors and nurses are responsible for making decisions about mechanical ventilation and weaning $(27,32)$. Moreover, Caring of the mechanically ventilated patient requires that, the crucial knowledge is essential to understand the pathophysiology of pulmonary conditions that necessitate the ventilator therapy as well as how to monitor and intervene when appropriate knowledge of ventilation parameters and mode, in conjunction with the use of capnography - respiratory waveform monitoring, is essential (13). As a nursing staff, it is essential to know about knowledge regarding the various aspects like airway management, positioning, nutritional therapy, medication, communication, weaning of the patient and prevention of complication about the care of a patient on a mechanical ventilator are more essential of providing safe nursing care (14)

Care of the patient on mechanical ventilation is an everyday assignment in the critical care unit nurses. Therefore, it is essential that the nursing staff applies knowledge and skills in order to provide effective care to the patients.So, the training program is essential to improve nurse's knowledge and skill regarding nursing care of patients on mechanical ventilators, this will improve the quality of nursing care (18). 


\subsection{The aim of the study}

To evaluate the effect of a structured training program on intensive care nurses performance. It will be achieved through:

1. Pre assessment of the nurse's knowledge and practice regarding nursing care of the patient on a mechanical ventilator.

2. Accordingly develop and implement a structured training program for nurses.

3. Post assessment of the effectiveness of the structured training program for nurses

4. Knowledge, practice and sequentially, it is the effects on regarding nursing care of the patient on Mechanical ventilator

\section{Research hypothesis:}

1. There is a positive effect on nurses' performance before and after a structured training program.

2. There will be no correlation between the post test score and demographic variables of intensive care nurses' performance.

\section{Material and Methods:}

2.1 Research Design: A quasi-experimental pre and posttest research design was used.

2.2 Setting: This study, conducted in intensive care units of two teaching hospitals, Al-Shabaab, and Al- Khartoum in Khartoum, Sudan.

2.3 Sample: A purposive sample of nurses working in the intensive care units ( 80 nurses), of the two hospitals, (50 nurses) from Khartoum teaching hospital, and (30 nurses) from Al-Shabaab teaching Hospital, who holds a bachelor and master degree were selected for the study.

2.3 Tool of data collection: Data for the present study was collected through two tools.

Tool I: The instrument consisted of three parts:

- Part one; was related to the socio-demographic and professional data, It includes age, years of experience,qualification and nurses received specific courses in mechanical ventilation.

- Part two;developed by researchers, according to the literature review $(5,11,12,13,23)$, includes 24 items related to knowledge regarding nursing care of patients on the mechanical ventilator (Indication of mechanical ventilation, ventilators setting and modes,complications of mechanical ventilation, follow up and weaning criteria). They were assessed by using correct and not correct.

- Part three: a checklist of care of the mechanically ventilated patients developed and validated by the researcher was used to assess skills and nursing management for the mechanically ventilated patient. They were assessed by using done and not done. It includes:

A) Dealing with a mechanical ventilator ( 3 items and 22 sub-items). Item one: Ventilator setting (9 sub items). Item two: Care of the ventilator ( 8 sub-items). Item three: Weaning process ( 5 sub-items).

B) Care of mechanically ventilated patient (10 items and 50 sub-items). Item one Oxygenation and ventilation ( 9 sub-items), Item two: Circulation and perfusion (6 sub-items).Item three: Patient comfort and pain control (4 subitems).Item four:Mobility \& safety (5 sub-items).Item five: Nutrition therapy (5 subitems).Item six:Patient needs (3 sub-items).Item seven:Assess patient for weaning criteria (6 subitems).Item eight: Care of mechanically ventilated patient during weaning (3 sub-items).Item nine: Care about disconnection from mechanical ventilation(4 sub-items). And item ten: Teaching on discharge (5 sub-items).

Tool II: McCloskey/Mueller Satisfaction Scale (MMSS) is being used to measure nurse satisfy / dissatisfy from their work in the ICU (Mueller \& McCloskey 1990).

2.4 Scoring system: For the knowledge items, a correct response was scored one and the incorrect zero for each area of knowledge. These scores were converted into a percent score. The maximum score is above $75(100 \%)$ and the least is zero $(0.00 \%)$. Whereas poor knowledge scored $<50 \%$ grades; average knowledge scored $50-69 \%$ grades, $70-85 \%$ grade was considered good, very good knowledge scored $85-95 \%$ grads and Excellent knowledge scored $95-100 \%$ The practical correct response was scored one and the incorrect zero. For each area, the scores were summed up and divided by the number of items giving a mean score.

These scores were converted into a percent score. Regarding practical items, score $<60 \%$ was evaluated unsatisfactory, while score $\geq 60 \%$ was considered satisfactory.

\subsection{Method}

- Permission to conduct the a structure the training program was obtained from the director of the Primary Health Care and Health Education Center, University of Gezira,Sudan, and hospital administrators of Al- 
Shabaab and AL Khartoum Teaching Hospitals.

- Content validity for study Tool was established by a jury of five experts' professors from medical-surgical nursing, nursing education and nursing administration. Accordingly, necessary modifications were done.

- The tool was tested for their reliability using Cronbach's alpha $=0.919$.

- The intervention was developed in the English language to cover the relevant theoretical and practical aspects of critical care of ventilated patient.

- The researchers were clarified to the participating nurses any misconceptions and the expected time for completing the tool was about 25-30 minutes

- A pilot study was conducted on $10 \%$ of the sample ( 8 nurse) to test the feasibility and applicability of the study tools. Accordingly, the necessary modifications were done.

- After completion of data collection, the necessary statistical analysis was done.

- Depending on the results of statistical analysis, a structured training program for improving nursing professional values was developed.

- Immediately after implementation of the structured training program, data collection was done to evaluate the s effectiveness of the educational program on nursing professional values.

\section{Process of the education program:}

\subsection{Preparation:}

1. Permission to conduct the structure, training program was obtained from the hospital administrators, the nursing directors and director of the training services unit in Al-Shabaab and AL Khartoum teaching hospitals.

2. Conduct the structure, training program was developed by the researchers after extensive review of the related literature $(7,21,19)$ after analysis of the results of initial data collection.

\subsection{Implementation:}

1- Developing Intended Learning Outcomes for the workshop based on the participants' needs and aim of the study.

2- Choosing the relevant active teaching strategies according to the information presented.

3- The workshop day was decided and the announcement was made one week before the structure, training program day,by hanging advertisement on the hospital's building walls to notify about the date, time and place of the workshop.

4- Each day consisted of 13 or 18 participants

5- The program was implemented in one week for the theoretical part and three weeks for demonstration the practical part.

6- The researchers followed the nurses under the study through the three shifts of the morning, afternoon and night.

7- The checklist was filled by the researchers according to the nursing care provided to patients using mechanical ventilation.

\subsection{The educational program consisted of:}

Theoretical part: knowledge about mechanical ventilation in, such as definition, types of the ventilators, setting and modes, and specific nursing care requirements of mechanically ventilated patients. (were implemented in one week).

Practical part: included how to perform ventilators setting according to the patient age and weight, how to detect alarm and provide manage accordingly, how to treat a patient according to the ABGs result, performing a septic EET suctioning, weaning and extubated patient. (Was implemented in three weeks for demonstration).

Different audio-visual materials were used as booklets and posters. These were used to facilitate teaching of each topic. Also, white board was used to explain some values as caring / performance.

Oral feedback in 10 minutes.

The same planned training program was conducted on different days. Due to the unavailability of participants in the same day and their busy schedules, the program was implemented from July to August 2018.

4. Evaluation phase: The same study tools were used to evaluate the effect of the structure-training program on the nurse's performance by comparing the results before training program with those after implementation of the training program.

\section{Ethical consideration:}

- An informed consent was obtained from (80) intensive care nurses after the researcher clarify the aim of the study before starting the questioner.

- Confidentiality, anonymity and privacy were assured. 
- Participation was on a voluntary basis.

- $\quad$ All the nurses had the right to withdraw from the study at any time without any drawbacks

\section{Statistical analysis:}

Data were verified prior to computerized entry. The Statistical Package for Social Sciences (SPSS) version 20.0 was used. Descriptive statistics were applied (e.g., mean, frequency and percentages). Statistical test includes': Kruskal-Wallis Test, Friedman Test was used for quantitative variables.A statistically significant difference was considered at $\mathrm{p}$-value $\mathrm{p} \leq 0.05$, and a highly statistically significant difference was considered at $\mathrm{p}$-value $\mathrm{p} \leq 0.001$.

\section{Result:}

Table (1): Distribution of the studied samples according to demographic data $(\mathrm{n}=80)$.

\begin{tabular}{|c|c|c|}
\hline 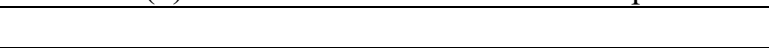 & Frequency & Percent $\%$ \\
\hline $\begin{array}{l}\text { Age: } \\
20-30 \\
31-40 \\
\geq 40\end{array}$ & $\begin{array}{l}40 \\
31 \\
9\end{array}$ & $\begin{array}{l}\text { Age: } \\
20-30 \\
31-40 \\
\geq 40\end{array}$ \\
\hline $\begin{array}{l}\text { Qualification } \\
\text { BSC } \\
\text { MSC }\end{array}$ & $\begin{array}{l}76 \\
4\end{array}$ & $\begin{array}{l}\text { Qualification } \\
\text { BSC } \\
\text { MSC }\end{array}$ \\
\hline $\begin{array}{l}\text { Experience } \\
1-5 \\
5-10 \\
\geq 10\end{array}$ & $\begin{array}{l}59 \\
14 \\
7\end{array}$ & $\begin{array}{l}73.8 \\
17.5 \\
8.8\end{array}$ \\
\hline $\begin{array}{l}\text { Nurses received specific courses in Mechanical } \\
\text { Ventilation: } \\
\text { Valid } \quad \text { Yes } \\
\quad \text { No }\end{array}$ & $\begin{array}{l}4 \\
76\end{array}$ & $\begin{array}{l}5.0 \\
95.0 \\
\end{array}$ \\
\hline Total & 80 & 100 \\
\hline
\end{tabular}

Table (1) shows that, the studied sample consisted of 80 nurses, 50\% of them aged ranged between 24- 30, $38.7 \%$ of them ranged between $31-40$, and only $11.3 \%$ were more than 40 years old. According to the nurse's qualification, the table shows that $95 \%$ of nurses under study were Bachelor (BSC) holder and only $5 \%$ have had a master degree. As regard the same table, it shows years of experiences $73.8 \%, 17.5,8.8 \%$ of them had $1-5$ years, 5-10 years, and more than 10 years of experiences respectively. In addition, the table shows that only 5\% of nurses under the study received specific course in mechanical ventilation, while $95 \%$ of them do not received specific course.

Table (2):Intensive care nurses' satisfaction from their work in the ICU.(n=80)

\begin{tabular}{|l|l|l|}
\hline Items & Number & Percent \% \\
\hline Satisfied & 43 & 53.8 \\
Dissatisfied & 37 & 46.2 \\
Total & 80 & 100 \\
\hline
\end{tabular}

Table (2) shows that $53.8 \%$ of nurses under study were satisfied with their work in intensive care units, while only $46.2 \%$ were not satisfied.

Table (3): Causes of intensive care nurse's dissatisfaction. .(n=80)

\begin{tabular}{|l|c|l|}
\hline Items & Number & Percent \% \\
\hline Lack of equipment & 42 & 52.51 \\
Low salary & 10 & 27.0 \\
Lack of training & 15 & 40.5 \\
Shortage of nursing staff & 34 & 42.5 \\
Poor environment & 23 & 28.7 \\
No job descriptions & 8 & 10 \\
\hline
\end{tabular}

Table (3) illustrates that $52.5 \%$ of nurses under study were not satisfied with their work in the ICU due to the lack of equipment, and $27.0 \%$ were due to low salary, $40.5 \%$ due to lack of training, and $42.5 \%$ due to the shortage of nursing staff. $28.7 \%$ said poor environment and only $10 \%$ thought of no job description. 
Table (4): Factors increasing intensive care nurse satisfaction. $(n=80)$

\begin{tabular}{|l|c|l|}
\hline Items & Frequency & Percent \\
\hline Available equipment & 50 & $62.5 \%$ \\
Enough staff & 48 & $60 \%$ \\
Continuous training program & 72 & $90 \%$ \\
Staff cooperation & 6 & $7.5 \%$ \\
\hline
\end{tabular}

Table (4) shows the $62.5 \%$ of nurses under study said available equipment could enhance work in the ICU, $60.0 \%$ said enough staff, $90 \%$ of them though the continuous training program can enhance the work, while $7.5 \%$ said staff training.

Table (5):The relationship between the training program and the age, qualification and years of experience of intensive care nurses.. $(\mathrm{n}=80)$

\begin{tabular}{|c|c|c|c|c|}
\hline Variable & No & Value of Correlation & P. value & Conclusion \\
\hline Age & 80 & -0.07 & 0.50 & \multirow{4}{*}{ There are no significant differences } \\
\hline BCS & 76 & \multirow{2}{*}{0.34} & \multirow{2}{*}{0.73} & \\
\hline MSC & 4 & & & \\
\hline Years of experience & 80 & 0.17 & 0.11 & \\
\hline
\end{tabular}

The table (5) shows there are no significant correlation of the training program and nurse's age, qualification, and years of experience P.value, 0.50 . ,0.73, 0.11, respectively.

Table (6):Intensive care nurses' performance (pre \&post-training program) in Al-Shabaab\& El-Khartoum

Teaching Hospitals. . $(\mathrm{n}=80)$

\begin{tabular}{|c|c|c|c|c|c|c|c|c|c|c|}
\hline & \multicolumn{5}{|c|}{ Pre training } & \multicolumn{5}{|c|}{ Post training } \\
\hline \multirow[t]{2}{*}{ Level } & \multicolumn{2}{|c|}{$\begin{array}{l}\text { Al-Khartoum } \\
\text { Hospital } \\
\mathrm{No}=50\end{array}$} & \multicolumn{2}{|c|}{$\begin{array}{l}\text { Al-Shabaab } \\
\text { Hospital } \\
\mathrm{No}=30\end{array}$} & \multirow{2}{*}{$\begin{array}{l}\text { Total } \% \\
\text { No }=80 \\
\%\end{array}$} & \multicolumn{2}{|c|}{$\begin{array}{l}\text { Khartoum } \\
\text { Hospital no }= \\
\text { No=50 }\end{array}$} & \multicolumn{2}{|c|}{$\begin{array}{l}\text { Al-Shabaab } \\
\text { Hospital } \\
\mathrm{No}=30\end{array}$} & \multirow{2}{*}{$\begin{array}{l}\text { Total } \% \\
\text { No }=80 \\
\%\end{array}$} \\
\hline & No & $\%$ & No & $\%$ & & No & $\%$ & No & $\%$ & \\
\hline Poor & 45 & 90 & 27 & 90.0 & 90.0 & 0 & 0 . & 0 & 0 & 0.0 \\
\hline Average & 5 & 10.0 & 3 & 10.0 & 10.0 & 1 & 2.0 & 2 & 6.7 & 3.8 \\
\hline Good & 0 & 0 & 0 & $\mathbf{0}$ & 0 & 18 & 36 & 12 & 46.7 & 37.5 \\
\hline Very good & 0 & 0 & 0 & $\mathbf{0}$ & 0 & 30 & 60.0 & 13 & 43.3 & 53.8 \\
\hline Excellent & 0 & 0 & 0 & $\mathbf{0}$ & 0 & 1 & 2.0 & 3 & 10.3 & 5.0 \\
\hline Total & 50 & $100 \%$ & 30 & $100 \%$ & $100 \%$ & 50 & $100 \%$ & 30 & $100 \%$ & $100 \%$ \\
\hline
\end{tabular}

Table (6) shows the pre the training program, $90 \%$ of intensive care nurses from Al- Khartoum and AlShabaab Teaching Hospital was poor and only $10.0 \%$ were passed. While at the post training program the performance enhanced and there were $2 \%, 60 \%, 36 \%, 2 \%$, excellent, very good, good, pass respectively in AlKhartoum, and $10.3 \%, 43.3 \%, 46.7 \%, 6.7 .3 \%$, excellent, very good, good, pass respectively in Al-Shabaab Teaching Hospital. Generally, the nurses' performance after the post-training program at both hospitals were enhanced and there were $5.0 \%, 53.8 \%, 37.5 \%, 3.8 \%$, excellent, very good, good, pass.

Table(7):Morbidity\& mortality rate in AL Khartoum and Al-Shabaab Teaching Hospitals pre \& post training program $(\mathrm{n}=80)$

\begin{tabular}{|c|c|c|c|c|c|c|}
\hline & & $\begin{array}{l}\text { Teaching } \\
\text { Hospitals }\end{array}$ & $\begin{array}{l}\text { No of } \\
\text { admission }\end{array}$ & $\begin{array}{l}\text { No of pts., received } \\
\text { mechanical ventilation }\end{array}$ & $\begin{array}{l}\text { No of } \\
\text { deaths }\end{array}$ & $\begin{array}{l}\text { Mortality } \\
\text { rate } \%\end{array}$ \\
\hline \multirow[t]{2}{*}{ Pre } & \multirow{2}{*}{$\begin{array}{l}\text { July } 2018-\text { July } \\
2018\end{array}$} & AL Khartoum & 824 & 152 & 110 & 72.4 \\
\hline & & Al-Shabaab & 594 & 151 & 115 & 76.2 \\
\hline \multirow{4}{*}{ Post } & \multirow{2}{*}{$\begin{array}{lll}\text { August } 2018- & - \\
\text { August } 2018 & \\
\end{array}$} & AL Khartoum & 783 & 136 & 75 & 55.2 \\
\hline & & Al-Shabaab & 687 & 187 & 94 & 50.4 \\
\hline & \multirow{2}{*}{$\begin{array}{l}\text { The enhancement } \\
\text { rate }\end{array}$} & \multicolumn{4}{|c|}{ AL Khartoum Teaching Hospital } & 17.2 \\
\hline & & \multicolumn{4}{|c|}{ Al-Shabaab Teaching Hospitals } & 25.8 \\
\hline
\end{tabular}

Table(7) illustrates the mortality among mechanically ventilated patient in the KTH pre training program was $72.4 \%$, while post-training program the present decreased to $55.2 \%$, and the enhancement rate was $17.2 \%$.In addition, table (8) illustrated that, the mortality among mechanically ventilated patient inAl-Shabaab Teaching Hospital pre training program was $76.2 \%$, while post-training program the percent decreased to $50.8 \%$, and the enhancement rate was $25.8 \%$.

\section{Discussion}

Nurses play a crucial role in the management of mechanically ventilated patients, and in the prevention of mechanical ventilation complications, it is challenging them to provide care for those patients. Nurses may feel frustrated, inadequate, and unsure whenever they fail to help those patients. It is anticipated that a training program 
for ICU nurses could enhance nurses' knowledge, attitudes, and competence about the management of mechanically ventilated patient (22). Hence, the current study was conducted to evaluate the effect of a structured training program on intensive -care nurses' performance. The current study findings showed that nurses' knowledge and performance toward mechanically ventilated patients changed significantly after training than before it.

The results showed that only $5 \%$ of the respondents were received special training courses in mechanical ventilation, while the majority $95 \%$ of ICU nurses' didn't received any specific course in mechanical ventilation, the outcome of mechanically ventilated patient depend completely on the proper nursing management, in spite of that there was a sever lack of continuous training programs, and the explanation was strongly that almost all of nurses were in continuous shifting, there was no a constant staff in one area so there is a need for continuous training and refreshing programs to keep high standard of nursing management providing to mechanically ventilated patient. This result also, indicated that either the hospital administration neglecting the importance of continuous training programs, or the disinterest of the respondent on attending any assigned program, and also may be due to the shortage of the staff there was no ability to release nurses to attend any program during the working hours. While in the study of (25), they highlight on their study about the importance of training aiming at both doctors and nurses for improving ICU performance. In the same line with $(2,16)$ found that training had positive contributions to the performance development.

This study demonstrated that more than half of nurses under study were satisfied with their work in the ICU, this result reflect their interest and understanding level of the nursing profession, because it is easy to link patient safety and patient satisfaction to nurse satisfaction. A satisfied nurses focus on their professional tasks, without being distracted by a negative environment, which leads to better performance, this finding agreed with (4), who reported that Health care managers realize that job satisfaction impacts on nursing staff retention. The study examined the job satisfaction of nursing staff at a government hospital. Just more than half of the respondents were generally satisfied. Feelings that nursing is worthwhile and satisfying, and financial stability at the hospital could promote staff retention.

Moreover, in the present study results, the nurses reported that less than half of them were dissatisfied, according to the shortage of nurses and lack of equipment in the ICU. Nursing shortages are one of the vexing problems in healthcare. This is a worldwide phenomenon, adding to this problem is that registered nurses (RNs) continue to leave their current positions and the profession at a high rate. It has been reported that up to $13 \%$ of new nurses consider leaving their jobs within one year. Job dissatisfaction is reported to be strongly associated with nurse turnover, and intent to leave thus highlighting the importance of understanding what promotes nursing staff job satisfaction (10). It has agreed with (8). He reported that many nurses use healthcare facilities as a temporary location to obtain training and experience. Then, they move with marketable skills to developed countries such as the US, the UK, Canada, and Australia. The present study, researchers of believed that, all mentioned justification for dissatisfaction were acceptable because if there was not enough equipment, and with the shortage of nursing staff, in the intensive care unit the nurses cannot perform their role properly, and this is itself a source of frustration for nursing administrators, because of the negative impact on quality care (7), highlights the relative importance of negative work outcomes on nurses' overall well-being. Strategies to reduce emotional exhaustion, enhance nurses' personal accomplishment and satisfaction with professional status, and accommodate shift preferences for work scheduling were suggested.

The findings of the current study revealed that, there were no statistically significant differences between nurse's age, years of experience, qualification, and the effectiveness of the training program. The explanation may be that the nurses' age of twenty four years to more than forty years, nurses' years of experience from one year to more than ten years and qualification level "BSC and MSC" and receiving general courses, had a nearly same level of knowledge and attitudes regarding mechanically ventilated patients in pre training program, this because the junior staff just follows the senior staff without adding a new information or knowledge. Nurses holding MSC were a few in numbers only $5 \%$ and may be they had no enough information about mechanical ventilation, and their training was insufficient for their work with mechanically ventilated patients. These findings were incongruent with (15), who found that the influence of age, education levels and work experience on training experience and knowledge transfer is significant.

The current study demonstrated that, nurses' performance regarding nursing management of mechanically ventilated patient was improved post training program, this may be due to their interest, and all of them feel that they need to be trained about dealing with mechanical ventilation, the result found the highest percentage of them agreed that the continuous training program may enhance their work in the ICU, and they agreed that the training program met their expectations regarding acquired knowledge about mechanical ventilation, they mentioned that the program had enhanced their knowledge and helped increase their awareness of the management of mechanically ventilated patient. This result agrees with (21) who found that staff training improved compliance with a pre-defined ventilator bundle.In additional, (16) who found in their study, the implementation of training program led to statistically significant improvements in students' knowledge and preventive measures $(\mathrm{P}<0.001)$. 
The present study finding goes in line with that of (30) who examined the effect of the training program on the practices of the patient and observed that it had a significant increase in the mean score of practice in the intervention group. A well, the current findings are congruent with that of (1) who carried out a similar study in Egypt and reported that there was a positive correlation between students who are having satisfactory knowledge and their health practices in pre and post intervention.

The current study revealed that the training program was effective in the reduction of mortality and morbidity rate in both studied Hospital, This findings agree with the study result of (20), where the structured training program was associated with a decrease in ICU mortality in two sites and improvement of nurses' performance.

\section{Conclusion}

From the findings of this study, it can be concluded that: the implementation of the nursing training program showed a significant improvement in the ICU nurses' level of knowledge and practice regarding caring for mechanically ventilated patients. The mortality and morbidity rate was reduced in both Al-Khartoum and AlShabaab Teaching Hospitals post training program

\section{Recommendations}

1- A continuous periodical training program for intensive care nurses to develop their knowledge, attitude, practices and skills in caring for mechanically ventilated patients.

2- Implementations of this intervention protocol to all new nurses at the Intensive Care Unit in Khartoum and Alshaab Teaching Hospitals and raise their ability to share their experience and knowledge.

3- Programs that aim to strengthen the nurse satisfaction, such as nurses counseling and modification programs are recommended for enhancing interpersonal relationships and improving the quality of care.

4- Information that nurses require and perceive to be relevant (e.g., ventilator modes, setting, types of alarms, ETT suctioning, weaning criteria) should be provided and readily accessible in the form of booklets.

\section{References}

1- Abd El- Salam AA, Eldeeb AM, \& Farahat FZ. The efficacy of learning package regarding vaginal infection and associated risk health behaviors. The Malaysian Journal of Nursing, 2018; 9 (4): 84-94.

2- Adhikari NKJ, Rubenfeld GD. Worldwide demand for critical care. Curr Opin Crit Care [Internet]. 2011 Dec [cited 2016 Oct 4]; 17(6):620-5. Available from: http://www.ncbi.nlm.nih.gov/pubmed/22067878 https://doi.org/10.1097/MCC.0b013e32834cd39c PMID: 22067878.

3- Bang KS, Kang JH, Jun MH, Kim HS, Son HM, Yu SJ, Kwon MK, Kim JS. Professional values in Korean undergraduate nursing students. Nurse education today. 2011 Jan 1;31(1):72-5.

4- Charlotte pietersen (2014). Job satisfaction of hospital nursing staff, sa journal of human resource management, 2014, 3 (2), 19-25, university of limpopo.

5- Deborah leader, rn.mechanical ventilation, what is mechanical ventilation. Updating june 02, 2010. Available from http://copd.about.com/od/copdglossarylo/g/mechanical-ventilation.htm . Accessed on 28/10/2012.

6- Hira HS, Mittal A. Evaluation of the predictors for duration of mechanical ventilation in respiratory intensive care unit. Lung India [serial online] 2006 [cited 2012 Nov 10]; 23:70-4. Available from: http://www.lungindia.com/text.asp?2006/23/2/70/44412. Accessed on 15/10/2012.

7- Haejung Lee, et al. (2014).Predictors of life satisfaction of Korean nurses. Volume 48, Issue 6, pages 632641, December 2004. Available form:

http://onlinelibrary.wiley.com/doi/10.1111/j.13652648.2004.03251.x/abstract?deniedAccessCustomisedMe ssage $=\&$ userIs Authenticated $=$ false. Accessed on 20/11/2012.

8- Hamdan S. Alsaqri (2014). A Survey of Intention to Leave, Job Stress, Burnout and Job Satisfaction among Nurses Employed in the Ha'il Region's Hospitals in Saudi Arabia. Phd thesis. RMIT University Melbourne Australia.

9- Jones, G.R., George, J.M., Hill, C.W.L. (2013) Contemporary Management New York, Irwin and McGraw Hills

10- Kalisch Bj, Lee H \& Rochman m. (2010), nursing staff teamwork and job satisfaction., journal of nursing management 18, 938-947, university of michigan school of nursing, ann arbor, mi, usa

11- K. Reinhart1 and G. Marx (2012). Effects of staff training on the care of mechanically ventilated. Available from bja.oxfordjournals.org/content/103/2/232..

12- Li, J. and Lambert, V. (2008), Job satisfaction among intensive care nurses from the People's Republic of China. International Nursing Review, 55: 34-39. doi: 10.1111/j.1466-7657.2007.00573.x. Available at http://onlinelibrary.wiley.com/doi/10.1111/j.1365-. Accessed on 20/12/2012.

13- Lewis, Heitkemper, Dirksen, et al. (2007). Medical Surgical Nursing, Assessment and Management of Clinical Problems. $10^{\text {th }}$ ed. MOSBY Elsevier, 11830 Waistline Industrial Drive. 1759 -1768.

14- Marya D, Zilberberg, and Andrew F Shorr(2010). Prolonged acute mechanical ventilation and hospital bed 
utilization in 2020 in the United States: implications for budgets, plant and personnel planning, available from http://www.biomedcentral.com/1472-6963/8/242. Accessed September 25/2010.

15- M C Lai, (2007). The investigation of the factors Impacting Training and Knowledge Transfer for Nurses in Taiwan Hospitals. Available from: acm.kuas.edu. tw - MC Lai- - 商業現代化學刊, 2007. Accessed on $15 / 12 / 2012$.

16- Zaghlou Mervat Gaber, Amasha Hadayat Abd El-Raof,(2019). Effectiveness of Training Program on Female's Students' Knowledge Regarding Vulvitis and its Preventive Measures: A Quasi-Experimental Study. IOSR Journal of Nursing a nd Health Science (IOSR-JNHS) e-ISSN: 2320-1959.p-ISSN: 2320-1940 Volume 8, Issue 1 Ser. VI. (Jan. - Feb .2019), PP 43-50

17- Morton P and Fontaine D, (2013). Critical Care Nursing. $10^{\text {th }}$ ed. Lippincott Williams \& Wilkins. P 533.

18- Nettina, Sandra M, Elizabeth J, et al. (2016). Lippincott Manual of Nursing Practice, $8^{\text {th }}$ ed. Lippincott Williams \& Wilkins. P 257.

19- Nursing and Midwifery Board of Australia. Enrolled nurse standards for practice. 2016. Available in http://www.nursingmidwiferyboard.gov.au/Codes-Guidelines-Statements/Professional-standards/enrollednurse-standards-for-practice.aspx, retrieved on 16/8/2018.

20- Rashan Haniffa, Yoel Lubell, Ben S. Cooper, Sanjib Mohanty,et al. (2017),Impact of a structured ICU training programme in resource-limited settings in Asia PLOS ONE | https://doi.org/10.1371/journal.pone.0173483 March 14, 2017

21- Reinhart1 and Marx, (2009. Effects of staff training on the care of mechanically ventilated. Available from bja.oxfordjournals.org/content/103/2/232.full access 0n 20/10/2012.

22- Robert L. Chatburn, (2010). determing the basis for taxonomy of mechanical ventilation. Youngston State University.

23- Parrillo, Joseph E., Dellinger, R. Phillip, (2008). Critical Care Medicine, Principles of Diagnosis and management in the adult, Mosby Elsevier, Philadelphia. P 510 - 540.

24- Rashan Haniffa1, Yoel Lubell, Ben S. Cooper, Sanjib Mohanty, Shamsul Alam , Arjun Karki etal. (2017) Impact of a structured ICU training programme in resource-limited settings in Asia, https://doi.org/10.1371/journal.pone.0173483

25- Riviello E, Letchford S, Achieng L, Newton M.(2011) Critical care in resource-poor settings: lessons learned and future directions. Crit Care Med. Brigham and Women's Hospital, Department of Internal Medicine, Boston, MA, USA. beth_riviello@post.harvard.edu; Apr; 39(4):860-7. https://doi.org/10.1097/ CCM.0b013e318206d6d5 PMID: 21297458

26- Rose Louise, Blackwood Bronagh, Egerod Ingrid, S Haugdahl Heges, Jose Hofhuis, Michael Isfort, et al.(2011). Decisional responsibility for mechanical ventilator and weaning: An international survey. Critical care 2011 Dec [cited 2012 Sept 4]; 15(6):295. Available from: URL:http://ccforum.com/content/15/6/R295

27- Sandra M. and Nettina, (2011). Manual of Nursing Practice. $7^{\text {th }}$ ed. Lippincott. Philadelphia. P $314-322$.

28- Smeltzer S, et al. (2010). Text book ofMedical Surgical Nursing. 12 ${ }^{\text {th }}$ ed. Lippincott, Philadelphia. P $212-$ 233.

29- Stechmiller JK, Yarandi HN. Job satisfaction among critical care nurses. College of Nursing, University of Florida, Gainesville $32610 . \quad 1992 \quad$ Nov; $1(3): 37-44$ available from http://www.ncbi.nlm.nih.gov/pubmed/1307905. Accessed on 25/10/2012.

30- Yarmohammadi S, Taheri G, Mousavi SS, Sheikhehpour M, Paykoub MH, \& Hashemian AH. The effect of education on knowledge, attitude and practice of patients with vaginitis. 2015; Advances in Biological Research, 9(3): 196-200.

31- H BU YASE (2014). "A study to assess the effectiveness of the repeated structured teaching program on progressive improvement in knowledge of nursing students regarding care of patient on mechanical ventilator in selected nursing colleges, Bangalore." Synopsis for registration of subjects for dissertation 